\title{
Capítulo 7
}

\section{Psicologia social crítica na periferia do capitalismo: a elaboração do sofrimento social e a luta por}

reconhecimento recíproco nas periferias Luis Galeão-Silva

\section{1}

Neste texto, nós discutiremos a relação entre a dimensão psicológica e a social como definidora do campo da psicologia social tanto no âmbito do conbecimento quanto na prática. A ação de reunir ou dividir esses termos poderia ser apenas uma questão de definição de categorias. Por exemplo, a gramática indica a reunião dos termos como psicossocial. E, no campo da psicologia social, temos tanto a defesa da forma psicossocial como a do hífen do termo psico-social. Propomos contribuir com o conhecimento dessa relação a partir da teoria social e da prática (comprometida com interesses coletivos). Deste modo, consideramos a relação entre o psíquico e o social determinada por mediações históricas. Tanto a sociedade define as condições de existência e formação da dimensão psicológica quanto há nesta dimensão particular diferentes reações - subjugadas, resistentes e criativas - às formas dominantes na sociedade. É na compreensão dialética e histórica das relações entre sociedade e psicologia que se encontra a especificidade do nosso ponto de partida, ou seja, a psicologia social definida a partir da teoria crítica da sociedade. Consideramos esta teoria por meio de dois modelos diferentes - o negativo e o reconstrutivo -, elaborados por teóricos e pesquisadores associados ao Instituto de Pesquisas Sociais de Frankfurt. Consideramos essas tendências como matrizes para definir essa relação em um contexto histórico específico, como a periferia do capitalismo que ilumina as formas gerais do tempo histórico. A periferia é, ao mesmo tempo, um posicionamento político e social em relação ao centro detentor do capital, do conhecimento e do poder, bem como um lugar produtor de identificações e identidades sociais de grupos que resistem e criam novas formas de expressão, memória e organização 
social. Neste sentido, a periferia pode ser compreendida como um significante para designar locais sociais de pessoas oprimidas e desconsideradas como cidadãs.

As consequências da dominação na dimensão psicológica são heterogêneas e fortemente determinadas por diferentes graus de elaboração do sofrimento social. Essas consequências vão de formulações patológicas até críticas. As expressões patológicas - o desrespeito, a humilhação e o preconceito - são formas de reação subjetiva à dominação. Outras formas apontam na direção da resistência à opressão e da criatividade - o reconhecimento recíproco, a capacidade de realizar atividades coordenadas e estéticas - ao serem críticas à dominação, sendo ou produtos acadêmicos, ou populares, cujo sentido é o da emancipação social.

Deste modo, destacam-se dois vetores de análise para a psicologia social: de um lado, aquele do grau de utilidade da irracionalidade do sofrimento; do outro, a elaboração que leva da reação até resistência e a realização de capacidades individuais e sociais por meio da luta por reconhecimento.

Consideramos que a chave para um projeto de psicologia social crítica na periferia do capitalismo é a descrição das condições psicossociais (da resistência e da regressão) das periferias do capitalismo e a reconstrução normativa por meio do reconhecimento recíproco formado na memória e na interação social. Deste modo, consideramos que esta comunicação dialoga com os seguintes conceitos: o psicossocial, a psicologia social crítica e o reconhecimento recíproco.

A relação da dimensão psicológica com a dimensão social é definidora do campo da psicologia social como pesquisa e atuação. Lembramos que entre o social e o psicológico há categorias intermediárias. São categorias que mediam essas relações, como o grupo, a identidade, o self ${ }^{1}$. Definir tanto as dimensões como as suas mediações poderia ser apenas uma questão de nomeação de categorias.

Consideramos que esta questão permite compreender a definição dessas categorias como uma necessidade histórica. Tanto a sociedade define as condições de existência e formação da dimensão psicológica, bem como suas mediações como linguagem, cultura e capital, quanto há nesta particularidade características resistentes às formas dominantes na sociedade. É na compreensão dialética e histórica das relações entre sociedade e psicologia que se encontra a especificidade da psicologia social definida a partir da teoria crítica da sociedade.

Nós reconhecemos que há outras definições de psicologia social crítica (FREITAS 1998; GUARESCHI, 2005; LIMA; CIAMPA, 2012). Mas, neste texto, atemo-nos à reflexão sobre as consequências para este campo de estudo da teoria crítica da sociedade nos séculos XX e XXI. Deste modo, recuperamos a noção de psicologia social crítica (kritischem Sozialpsychologie) apresentada por Theodor

1 O self é uma instância intermediária entre sociedade e os processos “mentais" para G. H. Mead (1952). 
Adorno (1970). A teoria crítica da sociedade precisa de ciências sociais que descrevam aspectos empíricos da sociedade, pois estes revelam as formas como a dominação se expressa, bem como a distância das possibilidades humanas demonstram a necessidade da crítica. Para que essas afirmações sejam compreendidas, é necessário apresentar os princípios da teoria crítica.

A relação entre a teoria crítica e a pesquisa empírica teve um grande desenvolvimento a partir dos pesquisadores ligados ao Instituto de Pesquisas Sociais de Frankfurt. Há dois conceitos fundamentais para compreender a teoria crítica da sociedade: a história social e a razão dialética. A história social é a resultante de conflitos que expressam a dominação social e negam a emancipação social. $\mathrm{Na}$ história, as relações entres os agentes sociais são regidas por um tipo especifico de razão: a dialética. Esta permite compreender a história como relações contraditórias entre afirmação e negação, possivelmente superáveis pela negação da negação. Estes dois conceitos são fundamentais para compreender o papel da ciência e da relação entre as dimensões social e psicológica. Esses pesquisadores produziram dois modelos diferentes de teoria crítica da sociedade e, consequentemente, sobre o papel da realidade social e de sua descrição pelas ciências sociais. Esses dois modelos são o negativo e o reconstrutivo. (NOBRE, 2004).

Estes modelos da teoria crítica da sociedade nos interessam por dois motivos: em primeiro lugar, por situarem as ciências sociais, em particular a psicologia social, na história social e na razão dialética por meio de um projeto de pesquisa interdisciplinar que reuniu a crítica e a pesquisa empírica; em segundo lugar, por desvelarem as contradições entre a sociedade e a psicologia a partir de diferentes ângulos: descritivo e normativo.

Adiantamos que a descrição dos conflitos sociais na história indica que a dominação organiza a distribuição do território como uma dimensão importante para descrever a dominação e a formação de movimentos de resistência e reconstrução. Por exemplo, Milton Santos (2002) e Erminia Maricato (2000) descrevem que o capital determina a distribuição do espaço a partir do seu valor como mercadoria, o que significa que, para além das aparências, a desigual concentração dos mais pobres nas periferias e centro deteriorado das cidades é uma determinação da desigual distribuição do capital. Nós destacamos que esses conceitos se desnudam a partir da realidade social da periferia do capitalismo. Mas vamos retomar os modelos e a forma como integram a pesquisa e a crítica para refletirmos sobre a relação entre o psíquico e o social.

O Instituto de Pesquisas Sociais de Frankfurt, em 1930, reuniu pesquisadores de diferentes áreas do conhecimento. Neste primeiro momento, a questão principal era como as massas, em vez de procurarem a emancipação, aderiram a regimes autoritários. Para tanto, era necessária uma definição da relação entre as partes e o todo da sociedade. Esta relação é definida, a partir da razão dialética, como 
uma relação contraditória entre a afirmação e a sua negação. A dimensão psicológica é uma parte deste todo; logo, também está submetida a essas determinações (WIGGERSHAUS, 2010).

Ser submetida a determinações do todo social (históricas) não significa que a parte (dimensão psicológica) seja uma mera cópia. A dimensão psicológica apresenta resistências a essas determinações. Essa resistência não se trata de uma natureza não dominada. Ocorre exatamente porque o todo social é dialético e por causa das contradições entre dominante e dominado torna possível a resistência da dimensão particular. Isto acontece por haver nesta dimensão particular as possibilidades de realização da emancipação do ser humano que existem no todo social. Ou seja, há na dimensão particular tanto a expressão da dominação quanto a da superação desta por meio das potencialidades criativas e de resistência inerentes às relações dialéticas entre afirmação e negação. A razão dialética revela que a afirmação - a dominação que se expressa na desigualdade social, o desrespeito - está em contradição com a sua negação - a resistência que se expressa na necessidade da alienação do trabalho para gerar o valor desigualmente distribuído e o senso de injustiça naqueles e naquelas que são desrespeitados.

Refletimos sobre os modelos a partir de suas consequências de fortalecimento e enfraquecimento para a análise política e epistemológica da relação entre psicologia e sociedade em uma sociedade de classes.

O modelo negativo da teoria crítica leva ao fortalecimento da crítica da relação entre todo e parte, o que, para uma compreensão do psicossocial, revela dois fatores fundamentais: a prevalência da dominação acima das aparências de harmonia ou entendimento e a relação dialética entre aspectos psicológicos e sociais. Ou seja, ressalta-se que não é apenas a descrição das condições a tarefa da psicologia social; é necessário, também, a crítica ao que o potencial humano é impedido de se realizar. $\mathrm{O}$ enfraquecimento da crítica ocorre quanto às consequências práticas desta abordagem. Ela apresenta uma dificuldade para articular ações sociais de resistência, bem como perceber os elementos de crítica surgidos da práxis nas periferias do capitalismo. Ao nosso juízo, falta-lhe uma teoria da ação social que contemple a variação e a criação em condições opressivas e que representem uma crítica prática à dominação. Podemos dizer que, para a psicologia social, falta uma crítica política que considere as ações práticas e os conhecimentos produzidos nas interações dos participantes de lutas sociais.

O segundo modelo da teoria crítica é o reconstrutivo. Habermas identificou um déficit filosófico na crítica negativa da razão. Esse déficit ocorre por esta crítica se transformar em tautológica. A razão dialética também estaria comprometida com a dominação por se comportar com o não idêntico aos seus conceitos tal qual um regime autoritário. Deste modo, a razão crítica à própria razão sem identificar o que poderia ser uma negação da negação dessa contradição entre idêntico e não-idêntico. A implicação dessa tautologia é não permitir identificar 
uma superação da contradição nas situações históricas como nos movimentos sociais e na política. A superação dialética no modelo crítico estava restrita à estética e, mesmo assim, suas possibilidades de realização da negação da negação eram muito reduzidas por ser uma esfera dominada por meio da indústria da produção e circulação de bens culturais: a indústria cultural.

A proposta de reconstrução do materialismo histórico a partir de suas bases normativas permitiu uma recuperação da crítica nas interações, o que inclui a estética e aspectos das ações instrumentais. Esta ênfase identificou uma relação menos determinada das estruturas sociais com as dimensões particulares por entender que a história se estende para a "integração social" por meio de experiências sociais. Essas experiências têm um núcleo normativo comum. Para essa teoria, o papel da normatividade passa a ser central para a regulação e os conflitos sociais. Esse modelo de teoria crítica identifica a interação social com a psicologia social, e suas análises corroboram com a definição do objeto da psicologia social como psicossocial.

Diremos que o fortalecimento da crítica desta segunda abordagem é a reconstrução da possibilidade de ação política e social. O enfraquecimento representado por esta é de um certo "déficit sociológico" ao propor alternativas normativas sem uma crítica à mediação do capital e da dominação na linguagem. Esse déficit é, em parte, diagnosticado por Axel Honneth no caso das relações de poder na linguagem. Consideramos que este é mais enfrentado posteriormente a partir de uma consideração das duas ênfases e do lugar social da crítica (VOIROL, 2012).

As análises da sociedade, no sentido da reconstrução, detectaram um certo arrefecimento das forças utópicas em uma sociedade do bem-estar social europeia. As ações normativas, em parte, contemplavam o respeito ao outro - apenas em parte, por continuar havendo a alienação das ações para finalidades heterônomas, fundamentalmente a reprodução do capital.

\section{2}

Nosso terceiro elemento para compreender a relação entre a psicologia e a sociedade é o lugar do sujeito no tempo e no espaço. O território é o local de onde interagimos com natureza e outros seres humanos na história:

Os homens fazem a sua própria história; contudo, não a fazem de livre e espontânea vontade, pois não são eles quem escolhem as circunstâncias sob as quais ela é feita, mas estas lhes foram transmitidas assim como se encontram. (MARX, 2011, p. 25)

A descrição dos conflitos sociais na história indica que a dominação organiza a distribuição do território como uma dimensão importante para descrever a dominação e a formação de movimentos de resistência e reconstrução. Por exemplo, 
Milton Santos (2002) e Erminia Maricato (2000) descrevem que o capital determina a distribuição do espaço a partir do seu valor como mercadoria, o que significa que, para além das aparências, a desigual concentração dos mais pobres nas periferias e centro deteriorado das cidades é uma determinação da desigual distribuição do capital. Nós destacamos que esses conceitos se desnudam a partir da realidade social da periferia do capitalismo.

As contradições do todo social se manifestam também nas suas partes, mesmo as mais distantes. Ao analisar a obra de Machado de Assis, o crítico Roberto Schwarz $(1977,1990)$ identificou que na periferia do capitalismo era possível revelar a condição humana em determinado momento histórico. Esta análise ressaltou a hipocrisia das "ideias fora do lugar" do século XIX - os ideais liberais no Brasil Imperial, uma sociedade distante da revolução industrial, na qual os ditos liberais mantinham escravos em vez de receberem a mais-valia do trabalho de empregados livres para vender sua força de trabalho. Consideramos que essa não é a idiossincrasia da elite brasileira, mas a contribuição dessa parte do sistema social do capital para revelar a contradição do liberalismo com a sua própria base material. Ou seja, o liberalismo é parte de um sistema social que se fundamenta na produção da mais-valia, seja por meio do trabalho livre ou escravo.

Mas as contradições do todo social se manifestam também nas suas partes, mesmo as mais distantes. Ao analisar a obra de Machado de Assis, o crítico Roberto Schwarz $(1977,1990)$ identificou que na periferia do capitalismo era possível revelar a condição humana em determinado momento histórico. Esta análise ressaltou a hipocrisia das “ideias fora do lugar” do século XIX - os ideais liberais no Brasil Imperial, uma sociedade distante da revolução industrial, na qual os ditos liberais mantinham escravos no lugar de receberem a mais-valia do trabalho de empregados livres para vender a sua força de trabalho.

Não concordamos com a noção de que haja um patamar normativo inferior na periferia. Defendemos que há uma normatividade condizente com as contradições sociais e, deste modo, as ações morais são expressão da sociedade. Por exemplo, um pobre no Brasil não é moralmente mais permissivo com o roubo do que o rico. Quando um pobre diz que vota em um político que "rouba, mas faz", ele não é mais permissivo do que um rico que diz não votar com essa justificativa. Para o rico, não é roubo a diferença de muito mais serviços públicos prestados aos ricos do que aos pobres, sendo que nos países centrais do capitalismo esta distância é bem menor. A iniquidade da distribuição dos bens sociais na periferia do capitalismo permanece como correlato da acumulação da mais-valia por uma fração da população mais rica. Esse lucro é exportado para os países centrais e elites locais por meio da manutenção de distorções normativas, que justificam a exploração de parte desta população periférica. E é produzido um lugar aquém da pobreza, o lúmpem para a teoria econômica, ou seja, o 
imprestável para o trabalho regular. Observamos formas de resistência e assujeitamento. Entendemos que estas considerações nos levam à obrigação de situar empiricamente e normativamenente nossos esforços críticos nas opressões e nas ações das pessoas que contradizem a gramática hegemônica da dominação. Essa exigência nos leva, necessariamente, a definir os territórios humanos nos quais habitam e circulam essas pessoas - nas periferias das cidades, nas ocupações irregulares, nas áreas de litígio entre populações que reivindicam as formas produtivas e de conhecimento tradicional como ponto de partida para formas de definição da solidariedade e da identidade: quilombola, caiçara e indígena.

\section{3}

A relação entre a dimensão psicológica e a sociológica é marcada por uma luta por reconhecimento. A revisão do modelo reconstrutivo nos leva à discussão da luta por reconhecimento, na qual a dimensão psicológica é intersubjetiva per se. Sua constituição permite observar a gramática dos conflitos sociais por reconhecimento - os quais pautam a identidade e a cidadania dos diferentes do padrão hegemônico: mulheres, homossexuais, transsexuais e travestis, negros, indígenas -, bem como a necessidade de consideração dos humilhados e dos marginalizados na história: o lúmpem proletariado e os desempregados de longa permanência.

Essa revisão recoloca no centro das relações as construções normativas a partir do conflito. Estas se dão em três dimensões de conflito, quais sejam: a integridade do corpo e o afeto, o respeito e o respeitar, e, por fim, o reconhecimento recíproco e a realização dos potenciais de ação (HONNETH, 2003).

Essas dimensões comportam a contradição do todo social expressas em suas próprias gramáticas: as relações amorosas, as relações do direito e as relações de solidariedade recíproca.

Para Axel Honneth, as três dimensões do reconhecimento recíproco - amor, direitos e solidariedade - permitem a compressão da dinâmica do processo de luta por reconhecimento e indicam, também, um ponto culminante do processo: o reconhecimento recíproco, que inclui a origem e o sentido dos processos de mudança social:

[...] a reprodução da vida social se efetua sob o imperativo do reconhecimento recíproco porque os sujeitos só podem chegar à auto-relação prática quando aprendem a se conceber na perspectiva normativa de seus parceiros de interação, como seus destinatários sociais (2003, p. 155-156).

A primeira dimensão é o amor, que, como dimensão do reconhecimento recíproco, é compreendido não como um sentimento romântico, mas como “[...] 
todas as relações primárias, na medida em que elas consistam em ligações emotivas fortes entre poucas pessoas, segundo o padrão de relações eróticas entre dois parceiros, de amizade e de relações pais/filhos" (HONNETH, 2003, p. 159).

A segunda dimensão é o reconhecimento jurídico e se distingue da primeira experiência de reconhecimento, o amor. O reconhecimento jurídico exige uma generalização cognitiva não necessária nas relações próximas: “[...] só podemos chegar a uma compreensão de nós mesmos como portadores de direitos quando possuímos, inversamente, um saber sobre quais obrigações temos de observar em face do respectivo outro: [...]" (HONNETH, 2003, p. 179).

A última dimensão do reconhecimento recíproco são a solidariedade e a estima social. Essa relação é dependente de condições históricas e sociais (HONNETH, 2003, p. 200). Entretanto, caso seja uma formação de estima fundamentada em hierarquias ou em estamentos (grupos sociais restritos na sua identificação de seus membros e que desvalorizam os diferentes da sua identidade), essa estima perde o seu caráter de reconhecimento recíproco.

Por fim, essas dimensões são indicativas de como podem surgir mudanças sociais. As expectativas normativas surgem de experiências concretas de reconhecimento e de sua negação por atos de não reconhecimento. Para cada dimensão do reconhecimento, há o seu desrespeito: ao amor, opõe-se a violação; aos direitos, o seu desrespeito e à estima social recíproca, a degradação e a ofensa (HONNETH, 2003, p. 211).

$\mathrm{O}$ amor, o direito e a comunidade de valores não são igualmente capazes de levar à tensão moral que caracteriza a luta social. Para tanto, é preciso uma generalização de objetivos que possam chegar a se apresentar como conflitos sociais e só o direito e a estima social se apresentam deste modo. A "luta social" passa a ter uma teoria sobre a sua semântica coletiva:

[...] luta social no contexto de nossas considerações -: trata-se do processo prático no qual experiências de desrespeitos são interpretadas como experiências cruciais típicas de um grupo inteiro, de forma que elas podem influir, como motivos diretores da ação, na exigência coletiva por relações ampliadas de reconhecimento (HONNETH, 2003, p. 256).

O que encontramos sobre a denominação de "comunidade" entre populações urbanas em grande vulnerabilidade social é exatamente um processo prático de reconhecimento mútuo e auto-realização que demanda uma ampliação do reconhecimento.

Por isso, para a psicologia social comunitária, a "comunidade de valores" se apresenta como a possibilidade de uma conceituação dinâmica e crítica do seu objeto de estudo. A comunidade deixa de ser uma indicação geográfica para descrever, ao mesmo tempo, as relações práticas que instituem novas expectativas de respeito e as ameaças à integridade corporal, aos direitos políticos e sociais e à dignidade. 
Deste modo, podemos concluir com as mediações da dominação, da ação produtora de respeito recíproco e ação coordenada:

a) As consequências da dominação na dimensão psicológica são heterogêneas e com diferentes graus de elaboração do sofrimento social. Essas consequências vão de formulações patológicas até críticas. As expressões patológicas - o desrespeito, a humilhação e o preconceito - são formas de reação subjetiva à dominação. Outras formas apontam na direção da emancipação - o reconhecimento recíproco, a capacidade de realizar atividades coordenadas e estéticas - ao serem críticas à dominação, sendo ou produtos acadêmicos, ou populares.

b) Consideramos dois vetores de análise para a psicologia social: de um lado, o grau de utilidade da irracionalidade do sofrimento; do outro lado, qual é a elaboração que leva da reação até resistência e a realização de capacidades individuais e sociais.

\section{4}

A chave para um projeto de psicologia social crítica na periferia do capitalismo é a descrição das condições psicossociais (da resistência e da regressão) das periferias do capitalismo e a reconstrução normativa por meio do reconhecimento recíproco formado na memória e na interação social. Nestes termos, não há, ainda, uma negação da negação da afirmação psicossocial e a sua negação psico-social. Temos que manter a contradição entre elas. Isto para mantermos nossa utilidade na luta social e na busca por ações e normatividades que superem a dominação.

Na sociedade (descritivamente) o centro é um polo de poder e controle do conhecimento, sua circunscrição é exatamente a expressão da dominação. Normativamente, o conhecimento com centro em toda parte é um princípio de interação do si mesmo como outro, no qual todos estão no centro. É preciso manter a compreensão de que é uma expectativa normativa - diríamos utópica - cuja constituição geral não podemos esperar, embora a sua imediatez esteja na contradição presente que a gesta.

Por fim, enunciamos, por meio da arte, que a periferia está para o todo da sociedade assim como o sertão está para o mundo:

“O sertão está em toda parte - o sertão está dentro da gente”. (Guimarães Rosa, 1988)

\section{Referências}

ADORNO, T. Erziehung nach Auschwitz 1966. In: . Erziehung zur Mündigkeit, Vorträge und Gespräche mit Hellmuth Becker 1959-1969: Herausgegeben von Gerd Kadelbach. Berlim: Suhrkamp, 1970. p. 88-104. 
FREITAS, M. F. Q. Inserção na comunidade e análise de necessidades: reflexões sobre a prática do psicólogo. Psicologia: Reflexão e Crítica, Porto Alegre, v. 11, n. 1, 1998.

GUARESCHI, P. A. Psicologia social crítica. Porto Alegre: EDIPUCRS, 2005.

GUIMARÃES ROSA, JOÃO. Grande Sertão: Veredas. Rio de Janeiro: Nova Fronteira, 1988.

HONNETH, A. The critique of power: reflective stages in a critical social theory. Boston: MIT Press, 1993. . A luta pelo reconhecimento. São Paulo: Editora 34, 2003.

LIMA, A. F.; CIAMPA, A. C. Metamorfose humana em busca da identidade na perspectiva da psicologia social crítica. Porto Alegre: Sulina, 2012.

MARICATO, E. Urbanismo na periferia do mundo globalizado: metrópoles brasileiras. São Paulo em Perspectiva, São Paulo, v. 14, n. 4, p. 21-33, 2000.

MEAD, G. H. Mind, self and society. Chicago: The University of Chicago Press, 1952.

NOBRE, M. Modelos de teoria crítica. In: NOBRE, M. (Org.). Curso livre de teoria crítica. Campinas: Papirus, 2008.

SANTOS, M. Espaço dividido: os dois circuitos da economia urbana dos países subdesenvolvidos. São Paulo: Edusp, 2002.

SCHWARZ, R. Ao vencedor as batatas. São Paulo: Duas Cidades, 1977.

. Um mestre na periferia do capitalismo. Machado de Assis. São Paulo: Duas Cidades, 1990.

VOIROL, O. Teoria crítica e pesquisa social: da dialética à reconstrução. Novos Estudos CEBRAP, São Paulo, n. 93, p. 81-99, 2012

WIGGERSHAUS, R. A Escola de Frankfurt: história, desenvolvimento teórico, significação política. Rio de Janeiro: DIFEL, 2010. 